\title{
Viability and Fate of Cryptosporidium parvum and Giardia lamblia in Tubular Anaerobic Digesters
}

1. Maureen N Kinyua

Affiliation address: Department of Civil and Environmental Engineering, University of South Florida, 4202 E Fowler Ave ENB 118 Tampa, FL 33620

Current address: Department of Earth and Environmental Engineering, Columbia University, 500 W. $120^{\text {th }}$ St. 918 S. W. Mudd Hall, 500, Manhattan, NY 10027 $\underline{\text { mk3855@,columbia.edu }}$

2. John Trimmer

Affiliation address: Department of Civil and Environmental Engineering, University of South Florida, 4202 E Fowler Ave ENB 118 Tampa, FL 33620

Current address: Department of Civil and Environmental Engineering, University of Illinois at Urbana-Champaign, 4151 Newmark Civil Engineering Laboratory, MC-250, 205 N. Mathews Avenue, Urbana, IL 61801

jtrimme2@,illinois.edu

3. Ricardo Izurieta Department of Global Health, University of South Florida, 4202 E Fowler Ave CPH 1127 Tampa, FL 33620

rizuriet@health.usf.edu

4. Jeffrey Cunningham

Department of Civil and Environmental Engineering, University of South Florida, 4202 E Fowler Ave ENB 118 Tampa, FL 33620

cunning@usf.edu

5. Sarina J. Ergas*

Department of Civil and Environmental Engineering, University of South Florida, 4202 E Fowler Ave ENB 118 Tampa, FL 33620

sergas@usf.edu

813-974-1119

*corresponding author 


\section{Abstract}

In many developing countries where pathogenic diseases of animal waste origin, such as giardiasis and cryptosporidiosis, are often prevalent, facilities are limited to treat livestock waste. However, household-scale anaerobic digesters are currently being promoted for bioenergy production from livestock manure. Since the effluent is often used as a fertilizer for food crops, it is critical to understand the effect of environmental conditions within household-scale digesters on the viability of Cryptosporidium parvum oocysts and Giardia lamblia cysts. In this study, key environmental parameters affecting (oo)cyst inactivation were measured in four tubular anaerobic digesters, which are a type of household-scale digester promoted for treatment of swine waste in rural Costa Rica. Interviews and participant observations were used to understand digester operation and maintenance procedures. Ambient temperatures $\left(21-24^{\circ} \mathrm{C}\right)$, near-neutral $\mathrm{pH}$, total ammonia nitrogen (TAN) concentrations $<250 \mathrm{mg} / \mathrm{L}$ and hydraulic retention times (HRTs) between 23 to 180 days were observed. Laboratory (oo)cysts inactivation studies were performed in bench-scale digesters, which were maintained under conditions similar to those observed in the field. Apparent first-order inactivation rate coefficients for Giardia lamblia and Cryptosporidium parvum were $0.155 \pm 0.041$

$0.054 \pm 0.006$ day $^{-1}$, respectively. Temperature and volatile fatty acids were the main factors contributing to Cryptosporidium parvum and Giardia lambliainactivation. A mathematical model was developed that predicts the concentration of (oo)cysts in the liquid effluent of tubular digesters like those observed in Costa Rica. A mathematical model was developed that predicts the concentration of (oo)cysts in the liquid effluent of tubular digesters like those observed in Costa Rica. Two dimensionless groups can be used to predict the performance of the digesters for inactivating pathogens; both dimensionless groups depend upon the average HRT in the 
digester. This is the first study to combine mathematical modeling with qualitative analysis, field and laboratory studies to predict the concentrations of (oo)cysts in tubular digester effluents.

Keywords: Cryptosporidium parvum; Giardia lamblia; Waste management, Livestock waste pathogens; Tubular digesters; Mathematical modeling 


\section{$1 \quad$ Introduction}

In many developing countries, poor management of livestock waste leads to human exposure to zoonotic pathogens. Exposure to pathogens in raw livestock manure occurs when farmers handle manure and apply it to soil and when pathogens are transferred from soil to food crops or to water bodies through runoff events (Erickson et al., 2006). In Costa Rica, Egypt, and Nigeria, for example, the presence of pathogens such asCryptosporidium sp., Giardia lamblia, Ascaris lumbricoides, Entamoeba histolytica, E. coli and fecal coliforms in raw vegetables sold in open-air markets has been attributed to use of irrigation water contaminated by livestock waste (Monge and Chinchilla, 1996; Damen et al., 2007; Eraky et al., 2014). According to the World Health Organization (WHO), Cryptosporidium parvum, Giardia lamblia, Campylobacter jejuni, Salmonella sp.and E. coli O157:H7 are the main zoonotic pathogens present in livestock waste that cause illness to humans (Dufour, 2012). In particular,Cryptosporidium parvum accounts for $23.7 \%$ of all worldwide waterborne disease outbreaks annually, while Giardia lamblia infects approximately 4\%(0.28 billion people) worldwide annually (Dufour et al., 2012). The low infective dose of these protozoan parasites increases the associated public health risk. One Giardia lamblia cyst or approximately nine Cryptosporidium parvum oocysts have been shown to cause illness in humans, especially young, old and immunocompromised individuals (Erickson et al., 2006; Haas et al., 1999). Symptoms from giardiasis and cryptosporidiosis include diarrhea or gastroenteritis, and these diseases can be fatal for immunocompromised individuals (Dufour et al., 2012). Gao et al. (2015) carried out a disease burden analysis for infections from Cryptosporidium sp. and Giardia sp. originating from livestock waste for communities in China and Ghana. This study found that infections from these parasites increased morbidity, mortality and disability burden. 
There are three types of small-scale anaerobic digestion systems commonly used in the developing world: fixed dome, floating drum and tubular. Unlike the floating drum and fixed dome digesters, tubular digesters do not require a high level of skilled labor to install, they are the easiest to operate, cost the least and can operate at a variety of temperatures. Therefore, tubular digesters are being promoted in Asia, Africa and Latin America. However, these digesters are easily damaged and have a shorter life span; 10 years compared to 15 - 20 years for the other two digester systems. Tubular digesters can improve the quality of life for those in the developing world by producing biogas that is most often used as a cooking fuel, but can also be used to heat water or buildings or to generate electricity for on-site use (Kinyua et al., 2016b). When biogas is used as a cooking fuel in place of firewood, these systems can be a useful tool to mitigate deforestation. Using biogas for cooking also results in decreased respiratory health concerns, especially for women and children who, due to their cultural and social roles, are disproportionally affected by indoor air pollution caused by burning wood or dung. Additionally, anaerobic digesters can assist in reducing water pollution by stabilizing dissolved and particulate organic matter in the waste. The treated effluent from anaerobic digestion contains primary nutrients (nitrogen, phosphorus) and is promoted forits use as a soil amendment to improve crop yields (Lansing et al., 2011).However, if pathogens in the livestock waste are not sufficiently inactivated during anaerobic digestion, then use of the effluent as a soil amendment may lead to public health concerns from human consumption of contaminated crops. Although prior studies have investigated $E$. coli inactivation during anaerobic digestion at moderate, mesophilic and thermophilic temperatures (Pandey et al., 2015) and Ascaris ovum (Manser et al., 2015), there is limited information on the fate of Cryptosporidium sp. and Giardia sp. (oo)cysts during anaerobic digestion of livestock wastes. Therefore, it is critical to understand the fate of 
pathogens during anaerobic digestion and to ensure that efforts to recover energy and nutrients from livestock waste do not lead to public health concerns from human consumption of contaminated crops.

Prior studies on the fate of Cryptosporidium sp.and Giardia sp.have investigated the susceptibility of these protozoan parasites to inactivation in the environment (water and soil)as a function of various factors, including: UV radiation (Betancourt and Rose, 2004), moisture content (Van Herk et al., 2004), concentrations of volatile fatty acids (VFA), temperature, $\mathrm{pH}$, and exposure to free ammonia $\left(\mathrm{NH}_{3}\right)$. Of particular importance in tubular digesters are VFAs, temperature, $\mathrm{pH}$, and free ammonia. Jenkins et al. (2002) and Olson et al. (1999) reported an increase in (oo)cyst inactivation rate as the temperature increased from $4^{\circ} \mathrm{C}$ to $25^{\circ} \mathrm{C}$ in soil and water. Jenkins et al. (1998) reported that free ammonia concentrations between 0.12 and $2.52 \mathrm{~g}$ $\mathrm{NH}_{3} / \mathrm{L}$ and $\mathrm{pH}$ levels above 9 inactivated oocysts in water. Concentrations of free ammonia in solution increase with increasing total ammonia nitrogen (TAN) concentrations, $\mathrm{pH}$, and temperature. As temperature increases, oocyst walls increase in permeability, allowing free ammonia to more easily penetrate into Cryptosporidium sp.oocysts. Once inside the (oo)cysts, free ammonia disrupts cell chemistry and structure throughprotein denaturation, making the cells vulnerable to inactivation (Kidd, 2011).

Chauret et al. (1999) and Kato et al. (2010) studied the inactivation of Cryptosporidium sp.and Giardia sp.(oo)cysts in mesophilic $\left(36^{\circ} \mathrm{C}\right)$ anaerobic digesters. Less than $30 \%$ removal per day ( $0.15 \log$ removal/day) was observed in both studies, while $90 \%$ removal $(1.0 \log$ removal) was observed within one hour at thermophilic temperatures $\left(47-55^{\circ} \mathrm{C}\right)$ (Kato et al., 2010). The authors attributed this reduction to the increased temperature damaging the oocyst walls and DNA, resulting in non-infective Cryptosporidium sp.sporozites. Medhat and Stafford 
(1989) investigated the effect of VFAs and temperature on inactivation of the protozoanEntamoeba histolytica (a parasite closely related to Giardia sp.) during mesophilic $\left(37^{\circ} \mathrm{C}\right)$ and thermophilic $\left(55^{\circ} \mathrm{C}\right)$ digestion of swine waste at a solids retention time (SRT) of 10 days. VFA concentrations were maintained between 1.5 and $3.0 \mathrm{~g}$ acetate/L. Maximum log removals were 0.5 and 4.0 at $37^{\circ} \mathrm{C}$ and $55^{\circ} \mathrm{C}$, respectively. VFAs influence pathogen inactivation rates by decreasing $\mathrm{pH}$, which acidifies pathogens' cells (Medhat and Stafford, 1989). It should be noted that although high VFA concentrations have been shown to cause inactivation of (oo)cysts, VFA concentrations greater than $600 \mathrm{mg}$ acetate/L have been shown to inhibit methanogenesis (Wang et al., 1999), so high concentration of VFAs should be avoided in anaerobic digestion. Cote et al. (2006) treated swine waste in a $20^{\circ} \mathrm{C}$ anaerobic sequencing batch reactor with a 20-day SRT and analyzed the concentration of oocysts in the influent and effluent. The level of oocysts in the effluent was below detection limits. Although the authors did not explicitly indicate the inactivation mechanism, VFA concentrations in reactors where (oo)cysts inactivation was observed were between 0.40 and $23.2 \mathrm{~g}$ acetate/L.Although a few studies have investigated the fate ofCryptosporidium sp.and Giardia sp.(oo)cysts during anaerobic digestion (Chauret et al., 1999; Cote et al., 2006; Kato et al., 2010), none of these studies have applied relevant conditions observed in tubular anaerobic digesters used in developing world contexts, which are operated at ambient temperatures (Kinyua et al.,2016b).

The overall goal of this study was to fill a critical research gap by investigating the viability and fate of Cryptosporidium parvum and Giardia lamblia (oo)cysts in small-scale tubular anaerobic digesters used to treat livestock waste in a developing world setting. The specific objectives that guided this research were to: (1) investigate the environmental conditions (HRT,SRT, solids loading rate)and carry out qualitative analysis to understand the operational 
and maintenance strategies for tubular anaerobic digesters treating swine waste in the Monteverde region of Costa Rica, (2) perform an inactivation kinetic study of (oo)cysts in the laboratory under environmental conditions ( $\mathrm{pH}$, temperature, VFA and TAN) similar to those observed in the field, (3) observe the distribution of (oo)cysts in the solid and liquid phases during anaerobic digestion, and (4) develop and apply a mathematical model of tubular anaerobic digesters to predict the concentration of viable (oo)cysts in tubular digester effluents. This study bridges environmental engineering and public health focus areas, including waste management and treatment, energy recovery, and pathogen inactivation, by identifying how small-scale tubular anaerobic digesters can be designed to promote not only livestock waste treatment and bioenergy recovery but also safe reuse of effluents for nutrient recovery. The results of this study are important to communities in developing countries where a high prevalence of giardiasis and cryptosporidiosis exists and where tubular digesters are being actively promoted to improve public health and the environment.

\section{Materials and Methods}

\subsection{Site Description and Tubular Digesters}

San Luis de Monteverde (N 10' 16.973" W 84' 47.882") is a rural mountain community located in the northwest region of Costa Rica with a mean annual temperature of $18^{\circ} \mathrm{C}$. San Luis de Monteverde has a population of approximately 500 people. The main economic activities are small-scale farming and eco-tourism. Installation of tubular digesters in the area was promoted by local educational and non-governmental organizations for energy production and to reduce livestock waste pollution of the watershed. Farmers in San Luis de Monteverde use Taiwanesemodel tubular anaerobic digesters to treat livestock waste and produce biogas for cooking. Four tubular digesters treating livestock waste in San Luis de Monteverde were studied in this 
research, and their operating parameters are summarized in Table 1. Based on a hydrodynamic study and CFD model presented in Kinyua et al. (2016a), the HRT of Digester 1 was 23 days. Using the same model the HRT of Digesters 2, 3 and 4 were estimated as 100, 180 and 55 days, respectively (Table 1). In addition, a survey was carried out and participant observations were used to gain insight into livestock and tubular digester management practices and operating parameters such as the volumetric flow rate (Q). Interviews were conducted in Spanish at the field sites. The survey instrument and responses are provided in the supplementary material (Table S.1).

\subsection{Determination of Inactivation Kinetics}

Three bench-scale reactors were setup at the University of South Florida (USF) Environmental Engineering laboratory (Tampa, FL) to determine the inactivation kinetics of Cryptosporidiumparvum and Giardialamblia (oo)cysts under environmental conditions similar to those measured in the field-scale tubular digesters. The bench-scale reactors were set up in 1.0-L glass bottles with a working volume of $0.9 \mathrm{~L}$. Reactor 1 was a bench-scale anaerobic digester and is described in Section 2.3. Reactor 2 contained phosphate-buffered saline (PBS) solution with added acetate $(300 \mathrm{mg} / \mathrm{L})$ and $80 \mathrm{~mL}$ of a $3 \mathrm{~g} \mathrm{NH} 4 \mathrm{Cl} / \mathrm{L}$ stock solution, resulting in a TAN concentration of $240 \mathrm{mg} \mathrm{NH}_{4}{ }^{+}$-N/L. PBS solution contained $0.0027 \mathrm{M} \mathrm{KCl}$ and $0.137 \mathrm{M} \mathrm{NaCl}$ at a pH of 7.4. Reactor 3 was a control reactor and contained only PBS solution without additional acetate or TAN. The purpose of Reactor 2 was to determine if VFA and TAN were the main contributors to (oo)cysts inactivation during anaerobic digestion.

Each of the three reactors contained two 10-mL Float-A-Lyzers (Spectrum Labs, Houston, TX). A Float-A-Lyzer is a dialysis device with a synthetic, semi-permeable membrane that allows solutes, such as TAN and VFA, to diffuse across the membrane, from areas of high 
concentration to low concentration, until equilibrium is reached. The porous membrane allowed solutes with a molar mass of up to $1000 \mathrm{~kg} /$ mole (1000 kilodalton) to pass through, while retaining the Cryptosporidium parvum and Giardialamblia (oo)cysts, which are too large to pass through the membrane. Each Float-A-Lyzer initially contained $2.5 \times 10^{4}$ viable(oo)cysts $/ \mathrm{mL}$ of Cryptosporidium parvum and Giardia lamblia suspended in PBS buffer solution. Viable Cryptosporidium parvum and Giardia lamblia (oo)cysts were obtained from Waterborne Inc. (New Orleans, LA).

Reactors were purged with nitrogen for 1 minute each time they were opened for sample collection to maintain anaerobic conditions. Reactors were incubated at $21^{\circ} \mathrm{C}$ in a Hach Model 205 compact incubator (Loveland, CO) for 24 days. Samples were analyzed for (oo)cysts viability as described below. The inactivation kinetics study was carried out in duplicate, with each study period lasting 24 days. This study period was based on a physical model and tracer study that showed a liquid hydraulic retention time (HRT) of approximately 23 days for a tubular digester treating livestock waste in Monteverde (Kinyua et al., 2016a).

Although Reactor 1 was intermittently fed(once per week) with swine waste feed, the (oo)cysts were held in the Float-A-Lyzers throughout the study period. Therefore, the system was modeled as a batch reactor regarding (oo)cysts inactivation kinetics. The inactivation rates of Cryptosporidium parvum and Giardia lamblia (oo)cysts were modeled according to first-order kinetics that have been usedpreviously(Jenkins et al., 1998) as:

$$
C_{\text {final }}=C_{\text {initial }} e^{-k t}
$$

where $C_{\text {final }}$ is the percentageof (oo)cysts viable at time $t(\%), C_{\text {initial }}$ is the percentage of (oo)cysts viable at time $\mathrm{t}=0$ days $(\%), k$ is the inactivation rate coefficient $\left(\mathrm{d}^{-1}\right)$ and $t$ is time (d). Equation (1) is based on a standard first-order kinetic model for pathogen inactivation, i.e., Chick's law 
(Chick, 1908). Other models have been developed for pathogen inactivation (Selleck et al., 1978; Selleck et al., 1980; Rennecker et al., 1999; Kim et al., 2002a and b). However, these models are usually employed to account for specific observations or phenomena, such as a required minimum Ct value when employing a chemical disinfectant. Furthermore, such models were often developed for the particular problem of chlorine disinfection of coliform bacteria. Since the exact mechanism of inactivation of (oo)cysts in anaerobic digesters is not yet clear, it seems reasonable to employ the more general Chick's law as a first approximation.

\subsection{Bench-Scale Anaerobic Digester}

The bench-scale anaerobic digester (Reactor 1) was initially inoculated with seed sludge from anaerobic digesters treating swine waste at the USF Environmental Engineering laboratory (Manser et al., 2015). Influent was prepared by blending swine waste with tap water to achieve a target volatile solids (VS) concentration of $20 \mathrm{~g} / \mathrm{L}$, similar to that found in the field tubular digesters' influent (Kinyua et al., 2016a). Tap water was used for this study because farmers in San Luis de Monteverde used chlorinated tap water to prepare influent for the tubular digesters. Swine waste was collected weekly from Twenty Four Rivers Farm in Plant City, FL. Reactor 1 was operated at a 24-day HRT. This digester was managed in a semi-continuous mode (fed once per week) and remained unmixed to simulate field conditions.

\subsection{Batch (Oo)cysts Adsorption Study}

Kinyua et al.(2016a) observed that solids accumulation and settling in tubular digesters lead to the formation of a biologically active floccular sludge layer with a long SRT. It is expected the (oo)cysts are distributed between the liquid phase and the solid sludge within the digesters. Therefore, adsorption of (oo)cysts onto the solids was examined to measure the distribution of (oo)cysts in the solid and liquid phases. Microcosms were setup in 50-mL bottles. 
Effluent $(50 \mathrm{~mL})$ from Reactor 1 was collected and centrifuged for 10 minutes at $3500 \mathrm{rpm}$ using a Thermo scientific CL2 centrifuge (West Palm Beach, FL). $15 \mathrm{~g}$ of solids from the dewatered sludge was placed into a clean $50 \mathrm{~mL}$ bottle. To this, $30 \mathrm{~mL}$ of supernatant was added. This mixture was spiked with $10^{6}$ non-viable Cryptosporidium parvum and Giardia lamblia(oo)cysts. Microcosms were initially purged with nitrogen gas for 1 minute, thoroughly mixed for 15 minutes, and incubated at $21^{\circ} \mathrm{C}$ in a Gyromax 727 orbital shaker incubator (Lafayette, CA) for 24 hours. Mixing was turned off to allow for settling of solids to simulate conditions in the field tubular digesters. After 24 hours, liquid and solid samples were analyzed for (oo)cysts concentration as described below. The batch (oo)cysts adsorption study was carried out in triplicate, with each study period lasting 24 hours.

\subsection{Cryptosporidiumparvum and Giardialamblia Detection and Enumeration}

During the inactivation kinetic study, the viability of (oo)cysts was determined using an exclusion/inclusion dye permeability assay described by Jenkins et al. (1997). Aliquots were stained with 4',6-diamidino-2-phenylindole (DAPI), propidium iodide (PI) and Cryptosporidiumparvum and Giardialamblia specific FITC labeled mouse monoclonal antibodies. Viable (oo)cysts and reagents were purchased from Waterborne, Inc. (New Orleans, LA). The blue DAPI stain attaches to DNA molecules in viable and nonviable (oo)cysts, while the red PI stain only penetrates (oo)cyst walls and attaches to DNA in nonviable (oo)cysts. The green FITC antibodies attach to the outer walls of (oo)cysts, which may be empty or may contain viable or nonviable DNA. Therefore, viable (oo)cysts were identified as those exhibiting the blue DAPI stain, but lacking the red PI staining. Using average numbers of (oo)cysts counted in two duplicate wells, the percent of viable (oo)cysts was calculated as: Percent viable $(\%)=100 \% \times$ 
Number of (oo)cysts exhibiting DAPI stain but lacking PI stain $\div$ (Total number of (oo)cysts Empty (oo)cysts).

For the batch adsorption study,liquid and solid phase samples were extracted and processed using the $\mathrm{ZnSO}_{4}$ density gradient method described by Kuczynka and Shelton (1999). A direct immunofluorescence protocol from Waterborne Inc. (New Orleans, LA), using fluorescein isothiocyanate (FITC) labeled mouse monoclonal antibody reagent, was used for Cryptosporidiumparvum and Giardialamblia (oo)cysts detection. Three aliquots were withdrawn from each phase. The apparent concentration of (oo)cysts in each phase was calculated as the average number of (oo)cysts counted per $\mathrm{g}$ total solids (TS) or $\mathrm{mL}$ (mass or volume of sample analyzed) from each of the three aliquots. True concentrations could be determined by dividing apparent concentrations by the fraction of (oo)cysts recovered in each phase. Recovery fractions are unknown, but were assumed to be the same in both phases. Accordingly, the distribution coefficient $\left(K_{d}\right)$, representing the partitioning of (oo)cysts between the solid and liquid phases ((oo)cysts/g TS / (oo)cysts/L), was calculated as: Apparent solid phase concentration ((oo)cysts/g TS $) \div[($ Apparent liquid phase concentration $(($ oo $)$ cysts $/ \mathrm{mL}) \times 1,000 \mathrm{~mL} / \mathrm{L})]$. Additionally, the percent of (oo)cysts in the liquid phase was calculated as: Apparent liquid phase concentration $(($ oo $)$ cysts $/ \mathrm{mL}) \times 30 \mathrm{~mL} \times 100 \% \div$ Total number of (oo)cysts enumerated in both phases. The percent of (oo)cysts in the solid phase was calculated in a similar fashion: Apparent solid phase concentration $((\mathrm{oo}) \mathrm{cysts} / \mathrm{g}) \times 15 \mathrm{~g} \times 100 \% \div$ Total number of (oo)cysts enumerated in both phases.

For microscopy, samples were examined using a Nikon Eclipse E200-LED (Melville, NY) equipped with a QBC ParaLens Advance LED fluorescent microscope attachment (Port Matilda, PA) with an excitation wavelength of 410-480 $\mathrm{nm}$ and an emission wavelength of above 
$520 \mathrm{~nm}$. For DAPI, a Leica DM 2000 fluorescent microscope (Allendale, NJ) with a UV filter (excitation wavelength of $340-380 \mathrm{~nm}$ ) was used. All samples were enumerated at $100 \times$ magnification using oil immersion lenses.

\subsection{Analytical Methods}

During the 5-week field study, all laboratory analyses were carried out at the University of Georgia Costa Rica campus (San Luis, Puntarenas, Costa Rica). Influent and effluent samples were collected and analyzed weekly from all four digesters for 5 weeks for $\mathrm{pH}, \mathrm{BOD}_{5}$, VS, TS, TN, TAN, and TP concentrations and $\mathrm{CH}_{4}$ content as described in Kinyua et al. (2016). COD and VFA measurements could not be carried out during the field-study because there were no facilities to dispose of the hazardous waste generated. Biogas production was only measured in Digester 1 using a wet tip gas meter (Wayne, PA). Floccular sludge from Digesters 1, 3 and 4 was also analyzed for TSS (S) as described in Kinyua et al. (2016). Due to logistical reasons, floccular sludge from Digester 2 was not analyzed.

During the 7-week bench-scale reactor and inactivation study, all laboratory analyses were carried out at USF Environmental Engineering laboratory (Tampa, FL). Influent and effluent samples were collected and analyzed weekly from the bench-scale anaerobic reactor for 7 weeks. Centrate from the bench-scale anaerobic reactor was obtained by centrifuging influent and effluent samples for 10 minutes at 3500 rpm using a Thermo scientific CL2 centrifuge (West Palm Beach, FL). $\mathrm{pH}, \mathrm{BOD}_{5}$, VS, TS, TN, TAN, and TP concentrations and $\mathrm{CH}_{4}$ content were analyzed as described above. Standard Methods (APHA, 2012) were used to measure soluble COD (5200B). Hach high range TNT test kits and a Hach DR 2800 spectrophotometer (Loveland, CO) were used to measure VFA (TNT 872). Biogas volume from Reactor 1 was collected in a 0.75 L SamplePro FlexFilm Air Sample Bag from SKC Inc (Eighty Four, PA) and 
measured by water displacement. Method detection limits (MDL) were (mg/L): COD (30) and VFA (50).

\subsection{Data Analysis}

Statistical analysis was performed using a one-way analysis of variance (ANOVA) test using GraphPad Prism version 6.0 for Windows 8 (San Diego, California). $p$ values less than 0.05 were considered statistically significant. Best-fit values of the inactivation rate coefficient (k) were determined by the 'fit' function in Matlab.

\section{Mathematical Model for (Oo)cysts Concentration in the Effluent from Tubular Digesters}

The purpose of this section is to develop a mathematical model that can predict the concentration of (oo)cysts in the effluent of tubular digesters. Such a model may be useful to guide the design, construction, and installation of the systems, and/or to lower farmers' risk of infection when the effluent is used as a soil amendment. Tubular digesters are typically operated in a semi-batch mode. At discrete time intervals (e.g. every day or every other day), fresh livestock waste (influent) is added to the digesters and a portion of the digester contents flows out of the digester. However, despite this mode of operation, Kinyua et al. (2016a) showed via a tracer study and computational fluid dynamics that the residence-time distribution of the tubular digesters is very close to that of a (continuous) completely mixed flow reactor (CMFR). Therefore, a mass balance for the (oo)cysts in the digester may be written as:

$$
\frac{d}{d t}[V C(t)+V S q(t)]=Q C_{I}(t)-Q C_{E}(t)-V k C(t)-V k S q(t)
$$

where $C(t)$ is the concentration of (oo)cysts in the liquid phase $((\mathrm{oo})$ cysts/L), $q(t)$ is the concentration of (oo)cysts absorbed in the digesters' total suspended solids ((oo)cysts/g), $S$ is the total suspended solids concentration in the digesters' floccular sludge layer $(\mathrm{g} / \mathrm{L}), C_{I}(t)$ is the 
time-varying (oo)cysts concentration in the influent of the digester $((\mathrm{oo}) \mathrm{cysts} / \mathrm{L}), C_{E}(t)$ is the(oo)cysts concentration in the effluent of the digester ((oo)cysts/L), $V$ is the tubular digester working volume $(\mathrm{L}), Q$ is the time-averaged flow rate $(\mathrm{L} / \mathrm{d})$, and $k$ is the inactivation rate coefficient $\left(\mathrm{d}^{-1}\right)$, assuming first-order inactivation kinetics. The objective of this section is to solve Equation (2) for $C_{E}(t)$ and thereby provide an estimate of the concentration of (oo)cysts in the digester effluent.

The right-hand side of Equation (2) did not include a term for (oo)cysts exiting the digester while sorbed onto solids. This is because the TS concentration $(0.77-4.99 \mathrm{mg} / \mathrm{L})$ in the effluent stream was much lower than the solids concentration in the floccular sludge layer (33.2 $420 \mathrm{mg} / \mathrm{L})$, i.e., $T S_{\text {effluent }} \ll S$. We verified that, for the tubular digesters, $Q T S_{\text {effluent }} q(t) \ll$ $Q C_{E}(t)$ and therefore did not need to be included in Equation (2).

To account for the sorption and desorption of (oo)cysts between the liquid phase and the floccular sludge layer, local equilibrium was assumed between the adsorbed and desorbed concentrations of (oo)cysts:

$$
q(t)=K_{d} C(t)
$$

where $K_{d}$ is the distribution coefficient, representing partitioning of (oo)cysts between the solid and liquid phases (L/g TS). Values for $K_{d}$ were determined from laboratory studies, as described in Section 2.4.

To aid in the solution of Equation (2), the following parameters are defined: $\tau=V / Q$, the HRT (day), $R=1+K_{d} S$, a retardation factor (dimensionless), $\gamma=k+1 /(\tau R)$, an effective rate coefficient accounting for both inactivation and advection $\left(\mathrm{d}^{-1}\right)$. Then, by also noting that $C_{E}(t)=C(t)$ in a CMFR, Equation (2) can be re-written as follows: 


$$
\frac{d C_{E}(t)}{d t}+\gamma C_{E}(t)=\frac{1}{R \tau} C_{I}(t)
$$

To solve Equation (2) or Equation (4), an equation needs to be assumed for $C_{I}(t)$, the concentration of (oo)cysts in the digester influent. Pigs have been shown to shed (oo)cysts in a sporadic pattern. When they are shedding, they have been shown to shed viable (oo)cysts for 10 to 28 days following a second-order polynomial distribution (Nydam et al., 2001; Guselle et al., 2003). Therefore, it is assumed that the concentration of (oo)cysts in the digester influent followed a second-order polynomial during the time period in which the pigs are infected:

$$
\begin{array}{cc}
t \leq 0 & C_{I}(t)=0 \\
0<t<t_{1} & C_{I}(t)=\frac{4}{\left(t_{1}\right)^{2}} C_{\text {max }} t\left(t_{1}-t\right) \\
t>t_{1} & C_{I}(t)=0
\end{array}
$$

where $t_{1}$ is the time interval over which the pigs are shedding (oo)cysts and $C_{\max }$ is the maximum concentration of (oo)cysts in the influent, which occurs at time $t_{1} / 2$.

The solution of Equation (4) subject to the initial conditions (Equation 5) is:

$$
\begin{gathered}
0 \leq t \leq t_{1} \quad C(t)=\frac{4 C_{\max }}{\gamma \tau R t_{1}}\left\{t-\frac{1}{\gamma}\left[1-e^{(-t \gamma)}\right]\right\} \\
-\frac{4 C_{\max }}{\gamma \tau R\left(t_{1}\right)^{2}}\left\{t^{2}-\frac{2 t}{\gamma}+\frac{2}{\gamma^{2}}\left[1-e^{(-t \gamma)}\right]\right\} \\
C(t)=C\left(t=t_{1}\right) e^{\left(-\gamma\left(t-t_{1}\right)\right)}
\end{gathered}
$$

It should be noted that an analytical solution to Equation (4) is possible because of the assumed form of $C_{I}(t)$ given in Equation (5). For different assumed forms of the influent concentration of (oo)cysts, it might be necessary to solve Equation (2) or Equation (4) numerically, e.g., with a finite-difference solution. The finite-difference approach was demonstrated by Kinyua (2015). 
Finally, the solution can be presented in terms of non-dimensional variables. By defining a non-dimensional concentration $\bar{C}=C / C_{\max }$ and a non-dimensional time $\bar{t}=t /(\tau R)$, Equation (6) can be re-written as follows:

$0 \leq \bar{t} \leq \bar{t}_{1}:$

$$
\begin{aligned}
\bar{C}(\bar{t})=\frac{4}{(1+D a) \bar{t}_{1}} & \left\{\left[1+\frac{2}{(1+D a) \bar{t}_{1}}\right] \bar{t}-\frac{\bar{t}^{2}}{\overline{t_{1}}}\right. \\
- & {\left.\left[\frac{2+(1+D a) \bar{t}_{1}}{(1+D a)^{2} \bar{t}_{1}}\right]\left[1-e^{-(1+D a) \bar{t}}\right]\right\} }
\end{aligned}
$$

$$
\bar{t}>\bar{t}_{1}:
$$

$$
\bar{C}(\bar{t})=\bar{C}\left(\bar{t}=\overline{t_{1}}\right) e^{-(1+D a)\left(\bar{t}-\bar{t}_{1}\right)}
$$

where $\overline{t_{1}}=t_{1} / \tau R$ and $D a=k R \tau$. Thus it is possible to see that the behavior of the tubular digesters (with respect to inactivation of pathogens) depends upon only two dimensionless groups, $\overline{t_{1}}$ and $D a$. The parameter $\overline{t_{1}}$ is a ratio of time scales, i.e., the ratio of the length of time that the pigs shed (oo)cysts to the digester HRT. It is, therefore, a dimensionless indicator of how long the pigs are infected. A value of $\overline{t_{1}}>1$ indicates that the pigs shed (oo)cysts longer than the (oo)cysts are in the digester (on average). The parameter $D a$ is a Damköhler number that indicates the extent of (oo)cyst inactivation within the HRT of the digester. A value of $D a>1$ indicates that a significant fraction of the cysts are inactivated before exiting the digester.

\section{$4 \quad$ Results and Discussion}

\subsection{Field and Bench-Scale Anaerobic Digester Performance and Environmental}

\section{Conditions}

Based on interviews with farmers, the field tubular digesters treating swine waste from four to ten pigs provided fuel for approximately four hours of cooking per day, which met the needs of an average family of five people. Average $\mathrm{pH}$, temperature, and TANconcentration in the four field tubular digesters, which were sampled over 5 weeks in Costa Rica, and from 
Reactors 1, 2 and 3, which were operated in the laboratory for a period of 7 weeks, are shown in Figure 1. VFA concentrations for Reactors 1,2 and 3are also shown in Figure 1. Average influent and effluent characteristics from the bench-scale anaerobic reactor (Reactor 1) and four tubular digesters are summarized on Table 2. Since VFAs were not assessed during the field study, VFA concentrations in the four digesters were assumed to be similar to those found in other studies treating livestock waste in tubular digesters (Usack et al., 2014). Influent soluble COD and VFA concentrations in Reactor 1 were $1.46 \pm 0.28 \mathrm{~g} \mathrm{COD} / \mathrm{L}$ and $306 \pm 66.3 \mathrm{mg}$ COD/L respectively. Effluent soluble COD and VFA concentrations in Reactor 1 were $1.08 \pm$ $0.16 \mathrm{~g} \mathrm{COD} / \mathrm{L}$ and $310 \pm 44.1 \mathrm{mg} \mathrm{COD} / \mathrm{L}$ respectively. These results indicate two important points.

First, with regard to the reduction of organic matter and solids, on average, the four tubular digesters exhibited $\mathrm{BOD}_{5}$ and VS removal efficiencies of approximately $98 \%$ and $87 \%$, respectively, while removal efficiencies in Reactor 1 were significantly lower. Process modeling in Kinyua et al. (2016a) revealed that solids settle and accumulate in these tubular digesters over time, resulting in the formation of a biologically active floccular sludge layer with a SRT that is higher than the mean liquid HRT. Due to the combined effects of the accumulation of solids and the conversion of organic substrate to biogas, tubular digesters can achieve higher removal of solids and associated organic matter than other types of digesters. Lansing et al. (2010) found that reported VS removal efficiencies among completely-mixed and non-mixed baffled digesters averaged approximately $50 \%$, similar to the removal observed in this study's Reactor 1 . The reduction of TP observed in the tubular digesters also provides evidence for solids accumulation, as a significant fraction of TP is associated with the solids (Lansing et al., 2010; Kinyua et al., 2016a). 
Second, $\mathrm{CH}_{4}$ content of the biogas was similar in Reactor 1 and in the tubular digesters. In the tubular digesters, $\mathrm{CH}_{4}$ content ranged from $60 \%$ to $71 \%$, while the $\mathrm{CH}_{4}$ yield measured in Digester 1 averaged $0.204 \mathrm{~L} \mathrm{CH}_{4} / \mathrm{g}$ VS. The $\mathrm{CH}_{4}$ content and $\mathrm{CH}_{4}$ yield of Reactor 1 averaged $65 \%$ and $0.161 \mathrm{~L} \mathrm{CH}_{4} / \mathrm{g} \mathrm{VS}$, respectively. These results are similar to those reported in previous studies. Tubular digesters in Peru, operated between $20^{\circ} \mathrm{C}$ and $25^{\circ} \mathrm{C}$, exhibited $\mathrm{CH}_{4}$ contents between $60 \%$ and $67 \%$, and the average $\mathrm{CH}_{4}$ yield was calculated to be $0.22 \mathrm{~L} \mathrm{CH}_{4}$ / g VS (Ferrer et al., 2011). Lansing et al. (2010) co-digesting swine waste with used cooking grease in tubular digesters at an average temperature of $25.5^{\circ} \mathrm{C}$, reported similar $\mathrm{CH}_{4}$ content, between $63 \%$ and $70 \%$, with a $\mathrm{CH}_{4}$ yield of $0.31 \mathrm{~L} \mathrm{CH}_{4} / \mathrm{g} \mathrm{VS}$, which was higher than this study. The greater level of biogas production and $\mathrm{CH}_{4}$ yield observed by Lansing et al. (2010) was likely attributable to the fact that swine manure was being co-digested with used cooking grease, a carbon-rich material known to have a positive effect on biogas production (Cirne et al., 2007).

One of the main objectives of this study was to replicate the environmental conditions observed in the tubular digesters in the laboratory. From Figure 1 and Table 2, pH, temperature, TAN and VFA concentrations in the bench-scale laboratory reactors were within the range observed in the field digesters, except for Reactor 3, which was used as a control to investigate the effect of TAN and VFA on inactivation rates. The environmental conditions replicated in the laboratory were similar (besides the solids accumulation and settling)for the inactivation rate kinetics studies to be carried out.

\subsection{Inactivation of Cryptosporidium parvum and Giardia lamblia}

Inactivation kinetics for Cryptosporidium parvum and Giardia lamblia (oo)cysts in the three bench-scale reactors are shown in Figure 2. A fit of the inactivation model (Eq. (1)) to the observed data from Reactor 1 is also illustrated in Figure 2. The best-fit values of the inactivation 
rate coefficients were determined by performing a linear regression on Equation 1 for Reactor 1. The linear regression was done in Microsoft Excel. Cryptosporidium parvum had a rate coefficient of $0.054 \pm 0.006$ day $^{-1}$ for $95 \%$ confidence $\left(\mathrm{R}^{2}=0.98\right)$ and Giardia lamblia had a rate coefficient of $0.155 \pm 0.041$ day $^{-1}$ for $95 \%$ confidence $\left(R^{2}=0.89\right) .24$-day $\log _{10}$ removal rates are summarized inTable 3. A gamma distribution of inactivation rate coefficients following the work of Körmendy et al. (1999) and Rohan et al. (2015) was also derived, and the results are shown in Figure S.1. In this figure, a distribution of rate coefficients is used instead of a single value of the rate coefficient.

Very few studies have quantified (oo)cysts inactivation during anaerobic digestion. Cote et al. (2006) reported Cryptosporidium parvum and Giardia lamblia inactivation during psychrophilic anaerobic digestion of swine waste but did not indicate the specific log removal. At $37^{\circ} \mathrm{C}$, Kato et al. (2003) observed a 0.88 - 1.52 log removal/6 days for Cryptosporidium parvum when digesting biosolids from a municipal wastewater treatment plant. Reporting the specific log removal at temperatures under which the tubular digesters are operated is crucial to ensure that the risk of infection from either parasite is not underestimated, hence protecting the health of communities in which these systems are used. From these results, two conclusions were drawn.

First, there were no significant differences between percent removals in Reactors 1 and 2 for either Giardialamblia $(p=0.78)$ or Cryptosporidiumparvum $(p=0.29)$ (Figure 2); however, inactivation rates were lower in Reactor 3 (PBS control). These results suggest that at $20^{\circ} \mathrm{C}$ and neutral $\mathrm{pH}$, the presence of TAN and VFA significantly increased the inactivation rate of the (oo)cysts when compared with the control reactor. The results also suggest that other anaerobic digestion byproducts or microbial competition had an insignificant effect on (oo)cyst 
inactivation. Several studies have demonstrated that exposing (oo)cysts to free ammonia can increase the rate of inactivation (Jenkins et al., 1998; Reinoso et al., 2007). Highly soluble free ammonia molecules penetrate the (oo)cyst walls, denaturing cell proteins by disrupting intramolecular hydrogen bonds (Kidd, 2011). This process causes inactivation of the parasites.Reinoso et al. (2007) observed59.3\% (0.39 log removal) and 85.2\%(0.83 log removal) when they exposed Cryptosporidiumparvum oocysts to 5 and $50 \mathrm{mg} \mathrm{NH}_{3} / \mathrm{L}$, respectively, for 4 days at $25^{\circ} \mathrm{C}$. In this study, the free ammonia concentrations in Reactors 1 and 2 were below $0.005 \mathrm{mg} \mathrm{NH}_{3} / \mathrm{L}$. Since the free ammonia concentration was low, and the individual effect of TAN concentration was not investigated, a decisive conclusion cannot be made as to the effect of free ammonia at these low concentrations on the inactivation of (oo)cysts. However, these results do suggest that VFA may have played a more significant role in the inactivation of (oo)cysts. Short chain VFAs, such as acetate and propionate, commonly present during anaerobic digestion, have been shown to inactivate bacteria such as Salmonella sp. and parasites such as Ascaris sp. (Butkus et al., 2011; Chen et al., 2012). This inactivation is attributed to diffusion of VFA molecules across the pathogen membrane causing acidification of the cell (Butkus et al., 2011). The $\mathrm{pH}$ change in the cell also causes protein denaturation and DNA damage (Kidd, 2011). Although VFAs could not be measured during the field study, prior studies of well-functioning tubular digesters treating livestock waste have reported VFA concentrations of 300 to $600 \mathrm{mg} / \mathrm{L}$ (Usack et al., 2014), which were similar to values in Reactors 1 and 2. It should be noted that the individual effects of TAN and VFAs on inactivation were not independently investigated, since the objective of this study was to create environmental conditions similar to those observed in the field tubular digesters. In the future, it would be worthwhile to investigate which of these constituents significantly affected inactivation (free ammonia or VFA). In addition, given that 
inactivation of both (oo)cysts occurred in Reactor 3 as well (Figure 2 a and b), the temperature of $20^{\circ} \mathrm{C}$ also contributed to the inactivation of (oo)cysts over time. This further justifies the need for a more controlled experiment investigating which of the three environmental conditions temperature, free ammonia (TAN) or VFA- had the greatest impact on (oo)cysts inactivation.

The second conclusion was that the rate of Giardia lamblia inactivation was significantly higher than the rate of Cryptosporidiumparvum inactivation. This difference in inactivation is most likely due to the physicochemical characteristics of the Giardia lamblia cysts and the Cryptosporidium parvum oocysts. A Giardia lamblia cyst wall is 300 to $500 \mathrm{~nm}$ thick and is comprised of 2 layers (Dumétre et al., 2011). The outer layer is made from a matrix of cysteinerich proteins, and the inner layer is a membranous wall. A Cryptosporidiumparvum oocyst wall is 50 to $80 \mathrm{~nm}$ thick with 3 layers: an outer layer that is comprised of a glucose-rich glycocalyx carbohydrate membrane, a central layer formed from lipids and proteins and an inner wall made from a matrix of lectin proteins (Dumétre et al., 2011). Although the Giardia lamblia cyst wall is thicker, the multilayer composition and rigidity of the Cryptosporidium parvum oocyst wall adds complexity (Samuelson et al., 2013). This complexity may lead to slower inactivation of Cryptosporidium sp. compared to Giardia sp. This trend, in which Giardia sp. inactivation is greater than Cryptosporidium sp. under the same environmental conditions, has also been noted in other studies (Olson et al., 1999). Based on the first-order decay kinetics model used to estimate the inactivation rate coefficient, a similar percentage removal as that observed in Reactor 1 for Giardia lamblia could be achieved for Cryptosporidiumparvum oocysts under the same environmental conditions if contact time were increased by a factor of 9.75 . 


\subsection{Phase Distribution}

Results from the phase distribution study for Cryptosporidium parvum and Giardia lamblia (oo)cysts are shown in Figure 3. The concentration of (oo)cysts in the liquid phase was $1.49 \times 10^{7} \pm 1.25 \times 10^{5}$ and $1.33 \times 10^{7} \pm 7.50 \times 10^{5}($ oo $)$ cysts/L of Cryptosporidium parvum and Giardia lamblia, respectively. The concentration of (oo)cysts in the solid phase was 35,125 \pm 125 and 36,750 \pm 750 (oo)cysts/g TS of Cryptosporidium parvum and Giardia lamblia,respectively. Calculated $K_{d}$ valueswere $0.0024 \pm 0.00066 \mathrm{~L} / \mathrm{g}$ TS and $0.0028 \pm 0.00090$ L/g TS for Cryptosporidium parvum and Giardia lamblia,respectively. These results indicate that both parasites have a high affinity for biosolids during anaerobic digestion depending on the solids concentrations in the digester.

Although the difference in the fraction of both parasites in either phase was not significant $(p=0.08)$, the interactions between the (oo)cysts and solids, leading to their adhesion to solids,may be different. Zeta potential and ionic strength of the solution containing the (oo)cysts affects the surface charge and repulsion or attraction of (oo)cysts to solids. Zeta potential, which refers to the electrostatic repulsion force between particles with the same charge, decreases with increasing ionic strength (Hsu and Huang, 2002). As the zeta potential decreases, the (oo)cysts become more negatively charged at neutral $\mathrm{pH}$. This makes the (oo)cysts behave like colloidal particles adhering to the solids (Hsu and Huang, 2002). Since Cryptosporidium sp. oocysts tend to be more negatively charged than Giardia sp. cysts, the surface charge on Cryptosporidium sp. oocysts is likely the main contributing factor to their adsorption to solids. Although the surface charge of Giardia sp. is also negative, the hydrophobic nature of these cysts plays a more significant role in their adhesion to solids (Dai et al., 2004). This is due to the physicochemical characteristics of Giardia sp. cysts' outer wall. As discussed 
previously, the outer wall of Giardia sp. cysts is composed of cysteine-rich proteins that are hydrophobic in nature (Dai et al., 2004; Dumétre et al., 2011).

It should be noted that a preliminary study on (oo)cysts phase distribution over a longer period of time (21 days) was carried out to determine if the distribution changed with time. The preliminary results are shown in the supplementary material and indicate that some (oo)cysts resuspended in the liquid phase after 21 days (Table S.2). However, this time period is still substantially shorter than the 100-day SRT of the tubular digesters (Kinyua et al., 2016a).

\subsection{Predicted Concentrations of (Oo)cysts in Tubular Digester Effluent}

Modeled predictions of effluent concentrations of viable Cryptosporidiumparvum and

Giardia lamblia (oo)cysts, based on Equation 6, are shown in Figure 4 for Digesters 1, 3 and 4. Due to logistical reasons, floccular sludge from Digester 2 was not analyzed, so effluent (oo)cyst concentrations were not predicted for this digester. Figure 4 shows the predicted concentrations of the parasites exiting the digesters when the pigs undergo a temporary bout of illness and (oo)cysts are introduced into the digesters in a polynomial distribution as discussed in Section 3. To apply Equation6, seven input parameters are required: digester volume $V$, average flow rate $Q$, concentration $S$ of suspended solids in the floccular sludge layer, pathogen inactivation rate coefficient $k$, pathogen adhesion distribution coefficient $K_{\mathrm{d}}$, maximum influent pathogen concentration $C_{\max }$, and length of time $t_{1}$ over which pathogens enter the digester. Reactor parameters $V, Q$, and $S$ were determined as described in Section 2.1, and are reported in Table 1 and Table 2. Pathogen parameters $k$ and $K_{\mathrm{d}}$ were determined as described in Sections 2.2 and 2.4, and values are reported in Sections 4.2 and 4.3. Values of $C_{\max }$ were based on previous studies and were estimated to be $8.77 \times 10^{4}$ oocysts/g TS and $9.18 \times 10^{4}$ cysts/g TS for Cryptosporidium parvum and Giardia lamblia, respectively (Yui et al., 2014). The value of $t_{1}$ 
was also based on previous studies and was estimated to be 19 days (Nydam et al., 2001; Guselle et al., 2003). The model results predicted more than $99.9 \%$ removal in all three digesters within 75 days after an outbreak of Cryptosporidium parvuminfection. More than $99.99 \%$ removal of Giardia lamblia was predicted in the three digesters by day 20. This significant difference in removal between the two parasites can be attributed to the differences in the inactivation rate coefficients (Section 4.2).

At the time of this study, Digester 1 had been in operation for 5 years, while Digesters 3 and 4 were in operation for less than one year. The length of digester operation did not appear to influence the floccular sludge layer S concentration. More research is required to understand how the design and operating parameters in this type of digester influence the formation and concentration of solids in the floccular sludge layer. Differences in predicted effluent (oo)cysts concentrations between the three digesters were influenced by differences in farmers' operation of the tubular digesters. The HRTs (Table 1) and TS loading rates varied between the three digesters. TS loading rates were $0.28,0.069$ and $0.36 \mathrm{~g}$ TS/L-day for Digesters 1,3 and 4 respectively. Digester 4, with the highest TS loading rate, also had the highest solids $(S)$ concentration (Table 2). An increase in TS loading rate may encourage increased solids accumulation, forming a dense floccular sludge layer in the digester, which may promote further adhesion of (oo)cysts to the solids and retardation of (oo)cyst transport through the digester. Due to this adhesion of (oo)cysts to the solids, solids accumulation in the tubular digesters has its benefits; however, further research is needed to assess the fate of (oo)cysts during required maintenance of the tubular digesters. If periodic desludging of the tubular digester is required, best management practices need to be utilized to ensure safe handling and disposal of the biosolids. Taking into account the peak pathogen concentrations predicted for the three digesters 
(Figure 4) varies by less than an order of magnitude, it can be assumed that the predicted effluent (oo)cysts concentrations of all three digesters is somewhat similar.

Of the seven parameters listed above that affect digester performance, farmers and operators of tubular digesters may have control over $Q$, the average rate of water input into the digester. Therefore, to determine the effect of $Q$ (and, by extension, HRT) on the (oo)cysts effluent concentration, a sensitivity analysis was carried out using the dimensionless solution Equation 7. The conditions of Digester 1 were used as "base case" conditions; the corresponding values of the two dimensionless groups for Digester 1 are $D a=1.39$ and $\overline{t_{1}}=0.83$. Then, the volumetric flow rate $Q$ was halved and doubled, while assuming that the values of all other system parameters were unchanged. When the volumetric flow rate $Q$ is halved, the average $\operatorname{HRT}(\tau)$ is doubled, and thus $D a$ is doubled and $\overline{t_{1}}$ is halved. Conversely, when the volumetric flow rate $Q$ is doubled, the average $\operatorname{HRT}(\tau)$ is halved, and thus $D a$ is halved and $\overline{t_{1}}$ is doubled.The results from the sensitivity analyses are shown in Figure 5.

Decreasing the volumetric flow rate (water usage), and thereby increasing HRT, improves the digester performance with respect to pathogen removal in two ways. First, the (oo)cysts have longer residence time in the digester during which they may be inactivated; this is seen in the increase in $D a$. Second, if HRT increases relative to $t_{1}$, then it means that the length of time that the (oo)cysts are in the digester increases relative to the length of time over which they are entering the digester; this is seen in the decrease in $\overline{t_{1}}$. Although the HRT and TS loading rates in the tubular digesters were significantly different, all the farmers reported having enough biogas for four to seven hours per day, which was adequate to meet their daily household cooking needs. Therefore, increasing the HRT (i.e. decreasing dilution of the influent swine 
waste) may decrease the concentration of viable (oo)cysts in the effluent without affecting biogas production.

Lastly, the model predicted a significant decrease in the concentration of (oo)cysts in the effluent compared to the concentration of (oo)cysts in the raw swine waste during an infection outbreak. In addition, the lag time between an infection and when (oo)cysts appear in the effluent may allow farmers some time to divert the effluent from food crops.

Apart from biogas production, the reduction in pathogen concentration is an important environmental and public health benefit for communities with livestock using tubular digesters. The use of tubular digesters has gained popularity among dairy farmers in rural Costa Rica and is also used by dairy farmers in other regions of the world including Tanzania, Indonesia, Bolivia and Peru (Cortsen et al., 1995; Alvarex et al., 2009; Ferrer et al., 2011; Usack et al., 2014). Among livestock, cattle are the main reservoir for Cryptosporidium sp. (Dufour et al., 2012). Therefore, assessing how the environmental conditions and physical processes in tubular digesters affect the fate and viability of these protozoan parasites is crucial. In addition, some of the farmers using tubular digesters in San Luis de Monteverde co-digest cattle and swine manure. In San Luis de Monteverde and elsewhere in the developing world, farmers are often encouraged to use the digester effluent as a soil amendment to increase crop yields and alleviate the cost associated with purchasing mineral fertilizers (Kinyua et al.,2016b). Therefore, further research is needed to assess the risk of infection when farmers with cattle and/or swine handle the tubular digester effluent to apply to crops and when humans eat crops fertilized with this effluent. 


\section{Conclusions}

Cryptosporidium parvum and Giardia lamblia inactivation studies indicated that, at neutral $\mathrm{pH}$, a temperature of $21^{\circ} \mathrm{C}$ and VFA concentration of about $300 \mathrm{mg} \mathrm{COD} / \mathrm{L}$ resulted in approximately 90\% removal (1.56 $\pm 0.24 \log$ reduction) for Giardia lamblia and about 60\% removal $(0.55 \pm 0.01 \mathrm{log}$ reduction) for Cryptosporidium parvum over 24 days. TAN concentration of about $240 \mathrm{mg} \mathrm{NH}{ }_{4}{ }^{-} \mathrm{N} / \mathrm{L}$ may not have had a significant effect on inactivation.A tubular digester model was used to predict the concentration of viable (oo)cysts in the tubular digester effluents. The model indicated that volumetric flow rate (Q), which influencesHRT and solids loading ratewere the main contributing factorsinfluencing the concentration of viable (oo)cysts in the tubular digester effluent.

\section{Acknowledgements}

The authors acknowledge San Luis farmers (Olivier Garro, Mario Vargas and Xinia Araya), the Monteverde Institute and University of Georgia Costa Rica for their assistance with this research. The authors also acknowledge Fabricio Camacho for his assistance with logistics in Costa Rica, Jie Zhang and Merrill Peyton Dilbeck at the University of South Florida (USF) for their assistance with model development and reactor maintenance, Leigh West at USF's Center for Drug Discovery and Innovation for assistance with (oo)cysts enumeration, and Eric Schramm at Twenty Four Rivers Farm. This material is based upon work supported by the National Science Foundation under Grant Nos. 1156735 and 1243510 and the USF Graduate School Signature Research Fellowship program. Any opinions, findings, or conclusions expressed in this paper are those of the authors and do not necessarily reflect the views of the National Science Foundation or the University of South Florida. 


\section{References}

Alvarez R, Lidén G. Low temperature anaerobic digestion of mixtures of llama, cow and sheep manure for improved methane production. Biomass Bioenergy, 2009, 33: 527-33. doi:10.1016/j.biombioe.2008.08.012.

APHA. Standard methods for the examination of water and wastewater, 32nd ed.; American Public Health Association: Washington, DC, 2012.

Betancourt, W.Q., Rose, J.B. Drinking water treatment processes for removal of Cryptosporidium and Giardia. Vet. Parasitol.2004, 126, 219-234.

Butkus, M.A., Hughes, K.T., Bowman, D.D., Liotta, J.L., Jenkins, M.B., Labare, M.P. Inactivation of Ascaris suum by Short-Chain Fatty Acids. Appl. Environ. Microbiol.2011, 77(1), 363-366.

Chauret, C., Springthorpe, S., Sattar, S. Fate of Cryptosporidium oocysts, Giardia cysts, and microbial indicators during wastewater treatment and anaerobic sludge digestion. Can. J. Microbiol.1999, 45(3), 257-62.

Chick H. An investigation of the laws of disinfection. J. Hygiene, 1908, 8, 92-158.

Cirne, D.G., Paloumeta, X., Björnssona, L., Alvesb, M.M., Mattiassona, B. Anaerobic digestion of lipid-rich waste-Effects of lipid concentration. Renew. Energy. 2007. 32 (6), 965-975; DOI 10.1016/j.renene.2006.04.003.

Cortsen L, Lassen M, Nielsen HK. Small scale biogas digesters in Turiani, Nronga and Amani Tanzania. In: Furze, J, editor. Tubular Plastic Bio-Digesters in Tanzania, Vietnam, Zimbabwe and China, Ebeltoft, Denmark: University of Aarhus; 1995, p. 36-82.

Retrieved July 28, 2014 from http://www.journeytoforever.org/biofuel_library/biogasPlastictube.pdf.

Cote, C., Masse, D.I., Quessy, S. Reduction of indicator and pathogenic microorganisms by psychrophilic anaerobic digestion in swine slurries. Bioresour. Technol.2006, 97, 686691. 
Dai, X., Boll, J., Hayes, M.E., Aston. Adhesion of Cryptosporidium parvum and Giardia lamblia to solid surfaces: the role of surface charge and hydrophobicity. Colloids Surf. B Biointerfaces, 2004, 34, 259-263.

Damen, J.G., Banwat, E.B., Egah, D.Z., Allanana, J.A. Parasitic contamination of vegetables in Jos, Nigeria. Annals of African Medicine, 2007, 6(3), 115-118.

Dufour, A., Bartram, J., Bos, R., Gannon, V. Animal Waste, Water Quality and Human Health. IWA Publishing: London, UK., 2012.

Dumétre, A., Aubert, D., Puech, P-H., Hohweyer, J., Azas, N., Villena. Interaction forces drive the environmental transmission of pathogenic protozoa. Appl. Environ. Microbiol.2011, 78(4), 905-912; DOI 10.1128/AEM.06488-11.

Eraky, M.A., Rashed, S.M., Nasr, M., El-Hamshary, A.M.S., El-Ghannan, A.S. Parasitic Contamination of Commonly Consumed Fresh Leafy Vegetables in Benha, Egypt. $J$ Parasitol Res. 2014, 1-7. doi: 10.1155/2014/613960

Erickson, M.C., Ortega, Y.P. Inactivation of protozoan parasites in food, water and environmental systems. J Food Prot. 2006, 69, 2786-2808.

Ferrer, I., Garfí, M., Uggetti, E., Ferrer-Martí, L., Calderon, A., Velo, E. Biogas production in low-cost household digesters at the Peruvian Andes. Biomass Bioenergy, 2011, 35, 1668 1674; DOI 10.1016/j.biombioe.2010.12.036.

Gao, T., Wang, X.C., Chen, R., Ngo, H.H., Guo, W. Disability adjusted life year (DALY): A useful tool for quantitative assessment of environmental pollution. Sci. Total Environ., 2015, 511, 268-287: DOI10.1016/j.scitotenv.2014.11.048.

Guselle, N.J., Appelbee, A.J., Olson, M.E. Biology of Cryptosporidium parvum in pigs: from weaning to market. Vet. Parasitol. 2003, 113, 7-18: DOI 10.1016/S0304-4017(03)000396.

Haas, C.N., Rose, J.B., Gerba, C.P. Quantitative Microbial Risk Assessment. John Wiley \& Sons: New York, 1999. 
Hsu, B-M., Huang, C. Influence of ionic strength and $\mathrm{pH}$ on hydrophobicity and zeta potential of Giardia and Cryptosporidium. Colloids Surf. A: Physicochem Eng. Asp. 2002,201, 201206.

Jenkins, M. B., Bowman, D. D., Fogarty, E. A., Ghiorse, W. C. Cryptosporidium parvum oocyst inactivation in three soil types at various temperatures and water potentials. Soil Biol. Biochem. 2002, 34(8), 1101-1109; DOI 10.1016/S0038-0717(02)00046-9.

Jenkins, M.B., Anguish, L.J., Bowman, D.D., Walker, M.J., Ghiorse, W.C. Assessment of a dye permeability assay for determination of inactivation rates of Cryptosporidium parvum oocysts. Appl. Environ. Microbiol.1997, 63(10), 3844-3850.

Jenkins, M.B., Bowman, D.D, Ghiorse, W.C. Inactivation of Cryptosporidium parvum oocysts by ammonia. Appl. Environ. Microbiol.1998, 64 (2), 784-788.

Kato, Satomi, Fogatry, E., Bowman, D. Effect of aerobic and anaerobic digestion on the viability of Cryptosporidium parvum oocysts and Ascaris suum eggs. Int. J Environ. Health Res. 2003,13(2), 169-179; DOI 10.1080/0960312031000098071.

Kidd, S. Advances in molecular and cellular microbiology: Stress response in pathogenic bacteria. CAB International: Oxfordshire, UK., 2011.

Kim J, Tomiak R, Mariñas B. Inactivation of Cryptosporidium parvum oocysts in a pilot-scale ozone bubble-diffuser contactor: 1., Model development. ASCE J. Environmental Engineering, 2002a, 128(6), 514-521.

Kim J, Tomiak R, Rennecker J, Mariñas B, Miltner R, Owens J. Inactivation of Cryptosporidium parvum oocysts in a pilot-scale ozone bubble-diffuser contactor: 1., Model verification and application. ASCE J. Environmental Engineering, 2002b, 128(6), 522-532.

Kinyua, M.N. Energy production and effluent quality in tubular digesters treating livestock waste in rural Costa Rica. 2015. (Doctorate dissertation). University of South Florida, Tampa, FL.

Kinyua, M.N., Zhang, J., Camacho-Cespedes, F., Tejada-Martinez, A., Ergas, S.J. Use of physical and biological process models to understand the performance of tubular anaerobic digesters. Biochemical Engineering Journal, 2016a, 107; 35-44. doi:10.1016/j.bej.2015.11.017 
Kinyua, M.N., Rowse, L., Ergas, S.J. Review of Small-Scale Tubular Digesters in the Developing World, Renewable and Sustainable Energy Reviews, 2016b, 58; 896-910. doi.org/10.1016/j.rser.2015.12.324

Kuczynska, E., Shelton, D.R. Method for detection and enumeration of Cryptosporidium parvum oocysts in feces, manures and soils. Appl. Environ. Microbiol. 1999, 65(7), 2820-2826.

Körmendy, I., Körmendy, L., Ferenczy, A. Thermal inactivation kinetics of mixed microbial populations. A hypothesis paper. J.of Food Eng.1999. 38, 439-453.

Lansing, S., Martin, J.F., Botero, R.B., da Silva, T.N., da Silva, E.D. Wastewater transformations and fertilizer value when co-digesting differing ratios of swine manure and used cooking grease in low cost digesters. Biomass Bioenergy.2010, 34, 1711-1720: DOI 10.1016/j.biombioe.2010.07.005

Manser, N.D., Wald, I., Ergas, S.J., Izurieta, R., Mihelcic, J.R. Assessing the fate of Ascaris suum ova during mesophilic anaerobic digestion. Environ. Sci. Technol. 2015, 49(5), 3128-3135: DOI 10.1021/es505807a.

Medhat, A.E.F., Stafford, D.A. The fate of Entamoeba histolytica during sewage treatment using anaerobic digesters. Proceedings of IAWPRC conference, 17-20 April 1989: Guildford, UK., 1989.

Monge, R., Chinchilla, M. Presence of Cryptosporidium oocysts in fresh vegetables. J. Food Prot., 1996, 59(2), 202-203.

Nydam, D.V., Wade, S.E., Schaaf, S.L., Mohammed, H.O. Number of Cryptosporidiumparvum oocysts or Giardia spp cysts shed by dairy calves after natural infection. Am. JVet. Res.2001, 62(10), 1612-1615: DOI 10.2460/ajvr.2001.62.1612.

Olson, M.E., Goh, J., Phillips, M., Guselle, N., McAllister, T.A. Giardia Cyst and Cryptosporidium Oocyst Survival in Water, Soil, and Cattle Feces. J. Environ. Qual. 1999, 28(6), 1991-1996: DOI 10.2134/jeq1999.00472425002800060040x

Pandey, P.K., Biswas, S., Vaddella, V.K., Soupir, M.L. Escherichia coli persistence kinetics in dairy manure at moderate, mesophilic, and thermophilic temperatures under aerobic and anaerobic environments. Bioprocess Biosyst Eng. 2015, 38, 457-467 
Reinoso, R., Becares, E., Smith, H.V. Effect of various environmental factors on the viability of Cryptosporidium parvum oocysts. J. Appl. Microbiol.2007, 104, 980-986: DOI 10.1111/j.1365-2672.2007.03620.x

Rennecker J, Mariñas B, Rice E, Owens J. Inactivation of Cryptosporidium parvum oocyst with ozone. Water Research, 1999, 33(11), 2481-2488.

Rohan, M., Fairweather A., Grainger, N. Using gamma distribution to determine half-life of rotenone, applied in freshwater. Science of the Total Environment, 2015, 527/528, 246251. http://dx.doi.org/10.1016/j.scitotenv.2015.04.059

Samuelson, J., Bushkin, G.G., Chatterjee, A., Robbins, P.W. Strategies to discover the structural components of cyst and oocysts walls. Euk. cell. 2013, 12(12), 1578-1587.

Selleck R, Saunier B, Collins H. Kinetics of bacterial deactivation with chlorine. ASCE J. Environmental Engineering, 1978, 104(6), 1197-1212.

Selleck R, Saunier B, Collins H. Kinetics of bacterial deactivation with chlorine - Closure to discussion. ASCE J. Environmental Engineering, 1980, 106(5), 1000-1002.

Usack, J. G., Wiratni, W., Angenent, L.T. Improved design of anaerobic digesters for household biogas production in Indonesia: One cow, one digester and one hour of cooking per day. Sci. World J., 2014, 2014, 1-8: DOI 10.1155/2014/318054

Van Herk, F.H., McAllister, T.A., Cockwill, C.L., Guselle, N., Larney, F.J., Miller, J.J., Olson, M.E. Inactivation of Giardia Cysts and Cryptosporidium Oocysts in Beef Feedlot Manure By Thermophilic Windrow Composting. Comp. Sci. Util.2004, 12(3), 235-241.

Wang, Q., Kuninobu, M., Ogawaa, H.I., Katoa,Y. (1999). Degradation of volatile fatty acids in highly efficient anaerobic digestion. Biomass and Bioenergy, 16, 407-416.

Yui, T., Shibahara, T., Kon, M., Yamamoto, N., Kameda, M., Taniyama, H. Epidemiological studies on intestinal protozoa in pigs in Saitama, Japan. Japan Agri. Res. Quart., 2014, 48(1), 87-93. 


\section{List of Acronyms}

$\begin{array}{ll}\text { ANOVA } & \text { One way analysis of variance } \\ \text { CSTR } & \text { Completely Stirred Tank Reactor } \\ \text { DAPI } & \text { 4', 6-diamidino-2-phenylindole } \\ \text { FITC } & \text { Fluorescein Isothiocyanate } \\ \text { HRT } & \text { Hydraulic Retention Time } \\ \text { PBS } & \text { Phosphate-Buffered Saline } \\ \text { PI } & \text { Propidium Iodide } \\ \text { SRT } & \text { Solids Retention Time } \\ \text { TAN } & \text { Total Ammonia Nitrogen } \\ \text { TS } & \text { Total Solids } \\ \text { TSS } & \text { Total Suspended Solids } \\ \text { VFA } & \text { Volatile Fatty Acids } \\ \text { VS } & \text { Volatile Solids } \\ \text { WHO } & \text { World Health Organization }\end{array}$




\section{List of Equation Nomenclature}

$\mathrm{C}(\mathrm{t}) \quad(\mathrm{oo})$ cysts/L Concentration of (oo)cysts in the liquid phase

$\mathrm{C}_{\mathrm{E}}(\mathrm{t}) \quad(\mathrm{oo})$ cysts/L Effluent (oo)cysts concentration

$\mathrm{C}_{\mathrm{I}}(\mathrm{t}) \quad(\mathrm{oo})$ cysts/L Influent (oo)cysts concentration

$\mathrm{C}_{\text {final }} \% \quad$ Percent viable (oo)cysts measured at time $\mathrm{t}$

$\mathrm{C}_{\max } \quad$ (oo)cysts/L Maximum concentration of (oo)cysts shed by the pigs

$\mathrm{C}_{\text {initial }} \% \quad$ Percent viable (oo)cysts measured at time $\mathrm{t}=0$ days

$\bar{C} \quad$ Non-dimensional concentration

Da Damköhler number

$k \quad$ day $^{-1} \quad$ Inactivation rate coefficient

$\mathrm{K}_{\mathrm{d}} \quad \mathrm{L} / \mathrm{g} \mathrm{TS} \quad$ Distribution coefficient

Q L/day Flow rate

q(t) (oo)cysts/g Concentration of (oo)cysts absorbed in the digesters' total suspended solids

$\mathrm{R} \quad$ Retardation factor

S $\quad$ g TSS/L Total suspended solids concentration in the digesters' floccular sludge layer

$\mathrm{t}$ day Time

$\mathrm{t}_{1}$ day Time interval over which the pigs are shedding (oo)cysts

$\bar{t} \quad$ Non-dimensional time

$\overline{t_{1}} \quad$ Ratio of time scale

V L Tubular digester working volume

$\gamma \quad$ day $^{-1} \quad$ Effective rate coefficient accounting for both inactivation and advection

$\tau$ day Hydraulic retention time 


\section{List of Tables}

Table 1: $\quad$ Average operating parameters for the bench-scale anaerobic reactor (Reactor 1) $(n=7)$ and four tubular digesters $(n=5)$.

Table 2: Average influent and effluent characteristics from the bench-scale anaerobic reactor (Reactor 1$)(\mathrm{n}=7)$ and four tubular digesters $(\mathrm{n}=5)$.

Table 3: 24 -day $\log _{10}$ removal rates $(n=2)$.

\section{List of Figures}

Figure 1: Average operating parameters for the three bench-scale reactors $(n=7)$ and four tubular digesters $(n=5)$. Since VFA concentrations were not measured in the tubular digesters, reactor 1 and 2 VFA concentrations are compared with literature values

Figure 2: Inactivation kinetics of Cryptosporidium parvum oocysts and Giardialamblia cysts. Each data point represents the mean \pm standard deviation of four replicates, with approximately 150 (oo)cysts enumerated per replicate. The model curve shows the fitted first-order inactivation model for Reactor 1.

Figure 3: (Oo)cysts phase distribution for Giardia lamblia cysts and Cryptosporidium parvum oocysts at a mass of $15 \mathrm{~g}$ and $30 \mathrm{~mL}$ of supernatant $(\mathrm{n}=3)$.Error bars represent standard deviation.

Figure 4: $\quad$ Modeled predictions of effluent concentrations of viable Cryptosporidium parvum oocystsand Giardia lamblia cysts in the three tubular digesters. Note that the yaxisscales for the two parasites are different.

Figure 5: Sensitivity analysis of the effect of volumetric flow rate on (oo)cysts concentration in the tubular digester effluent. 
Table 1: Average operating parameters for the bench-scale anaerobic reactor (Reactor 1) $(n=7)$ and four tubular digesters $(\mathrm{n}=5)$.

\begin{tabular}{ccccccc}
\hline Parameter & \multirow{2}{*}{ Unit } & Reactor & Digester & Digester & Digester & Digester \\
& & $\mathbf{1}$ & $\mathbf{1}$ & $\mathbf{2}$ & $\mathbf{3}$ & $\mathbf{4}$ \\
\hline Working volume & $\mathrm{L}$ & 0.90 & 12000 & 9000 & 9000 & 9000 \\
Temperature & ${ }^{\circ} \mathrm{C}$ & 21 & 20.7 & 20.9 & 21.5 & 23.8 \\
& & \pm 0.10 & \pm 0.48 & \pm 0.00 & \pm 0.00 & \pm 0.75 \\
Influent flow & L/day & 0.048 & 543 & 90 & 50 & 164 \\
HRT & \multirow{2}{*}{ day } & 24 & \pm 0 & \pm 30 & \pm 4 & \pm 30 \\
\end{tabular}


Table 2: Average influent and effluent characteristics from the bench-scale anaerobic reactor (Reactor 1) (n=7) and four tubular digesters $(n=5)$.

\begin{tabular}{|c|c|c|c|c|c|c|c|c|c|c|c|}
\hline \multirow{4}{*}{$\begin{array}{c}\text { Parameter } \\
\text { BOD }_{5}\end{array}$} & \multirow{4}{*}{$\begin{array}{l}\text { Unit } \\
\mathrm{g} / \mathrm{L}\end{array}$} & \multicolumn{2}{|c|}{ Reactor 1} & \multicolumn{2}{|c|}{ Digester 1} & \multicolumn{2}{|c|}{ Digester 2} & \multicolumn{2}{|c|}{ Digester 3} & \multicolumn{2}{|c|}{ Digester 4} \\
\hline & & Influent & Effluent & Influent & Effluent & Influent & Effluent & Influent & Effluent & Influent & Effluent \\
\hline & & 0.927 & 0.567 & 5.09 & 0.030 & 2.99 & 0.126 & 12.4 & 0.155 & 15.0 & 0.074 \\
\hline & & \pm 0.14 & \pm 0.098 & \pm 0.30 & \pm 0.015 & \pm 1.26 & \pm 0.023 & \pm 2.45 & \pm 0.008 & \pm 1.5 & \pm 0.03 \\
\hline \multirow{2}{*}{ TS } & \multirow{2}{*}{ g TS/L } & 32.1 & 18.9 & 6.35 & 0.77 & 19.6 & 4.22 & 12.4 & 4.49 & 19.6 & 4.99 \\
\hline & & \pm 3.88 & \pm 2.60 & \pm 2.87 & \pm 0.25 & \pm 5.96 & \pm 3.60 & \pm 5.88 & \pm 1.39 & \pm 2.72 & \pm 0.53 \\
\hline \multirow{2}{*}{ VS } & \multirow{2}{*}{ g VS/L } & 20.0 & 12.2 & 5.17 & 0.58 & 15.4 & 0.81 & 9.75 & 2.26 & 15.9 & 2.26 \\
\hline & & \pm 1.32 & \pm 1.03 & \pm 2.44 & \pm 0.24 & \pm 5.36 & \pm 0.01 & \pm 5.08 & \pm 1.65 & \pm 1.22 & \pm 0.44 \\
\hline \multirow{2}{*}{ TAN } & \multirow{2}{*}{$\mathrm{mg} \mathrm{NH}_{4}{ }^{+}-\mathrm{N} / \mathrm{L}$} & 25.4 & 176 & 140 & 52.8 & 224 & 254 & 193 & 195 & 180 & 165 \\
\hline & & \pm 6.96 & \pm 56.5 & \pm 49.0 & \pm 4.66 & \pm 79.2 & \pm 16.9 & \pm 99.8 & \pm 7.54 & \pm 56.6 & \pm 52.8 \\
\hline \multirow{2}{*}{ Soluble TN } & \multirow{2}{*}{$\mathrm{mg} \mathrm{N} / \mathrm{L}$} & 298 & 219 & 300 & 49.3 & 319 & 227 & 350 & 186 & 513 & 303 \\
\hline & & \pm 30.7 & \pm 81.1 & \pm 23.6 & \pm 5.12 & \pm 120 & \pm 12.5 & \pm 75.0 & \pm 1.00 & \pm 112 & \pm 27.5 \\
\hline \multirow{2}{*}{ Soluble TP } & \multirow{4}{*}{$\mathrm{mg} \mathrm{PO}_{4} / \mathrm{L}$} & 154 & 521 & 402 & 33.9 & 573 & 228 & 333 & 25.0 & 503 & 139 \\
\hline & & \pm 67.0 & \pm 31.3 & \pm 126 & \pm 8.91 & \pm 72.0 & \pm 28.3 & \pm 131 & \pm 0.00 & \pm 81.0 & \pm 0.00 \\
\hline \multirow{2}{*}{ pH } & & 7.48 & 7.06 & 7.08 & 7.04 & 7.96 & 7.74 & 6.57 & 7.50 & 5.83 & 7.67 \\
\hline & & \pm 0.09 & \pm 0.057 & \pm 0.62 & \pm 0.14 & \pm 0.57 & \pm 0.19 & \pm 1.18 & \pm 0.14 & \pm 0.12 & \pm 0.09 \\
\hline $\mathbf{S}^{\mathrm{a}}$ & g TSS/L & \multicolumn{2}{|c|}{$\mathrm{n} / \mathrm{m}$} & \multicolumn{2}{|c|}{33.2} & \multicolumn{2}{|c|}{$\mathrm{n} / \mathrm{m}$} & \multicolumn{2}{|c|}{88.0} & \multicolumn{2}{|c|}{420} \\
\hline $\begin{array}{l}\text { Methane } \\
\text { content }\end{array}$ & $\%$ & \multicolumn{2}{|c|}{$\begin{array}{c}65 \\
\pm 0.0\end{array}$} & \multicolumn{2}{|c|}{$\begin{array}{r}71.0 \\
\pm 10\end{array}$} & \multicolumn{2}{|c|}{$\begin{array}{r}71.0 \\
\pm 10\end{array}$} & \multicolumn{2}{|c|}{$\begin{array}{c}60.8 \\
\pm 6.20\end{array}$} & \multicolumn{2}{|c|}{$\begin{array}{c}65.0 \\
\pm 5.40\end{array}$} \\
\hline CH vield & $\mathrm{L} \mathrm{CH}_{4} / \mathrm{g} \mathrm{VS}$ & \multirow{2}{*}{\multicolumn{2}{|c|}{$\begin{array}{c}0.161 \\
\pm 0.018\end{array}$}} & \multirow{2}{*}{\multicolumn{2}{|c|}{$\begin{array}{c}0.204 \\
\pm 0.099\end{array}$}} & \multirow{2}{*}{\multicolumn{2}{|c|}{$\mathrm{n} / \mathrm{m}$}} & \multirow{2}{*}{\multicolumn{2}{|c|}{$\mathrm{n} / \mathrm{m}$}} & \multirow{2}{*}{\multicolumn{2}{|c|}{$\mathrm{n} / \mathrm{m}$}} \\
\hline Chis yiera & added & & & & & & & & & & \\
\hline
\end{tabular}


Table 3: 24 day $\log _{10}$ removal rates $(n=2)$.

\begin{tabular}{cccc}
\hline Reactor & Unit & Cryptosporidium parvum & Giardia lamblia \\
\hline Reactor 1 & $\log _{10} / 24$ days & $0.55 \pm 0.098$ & $1.56 \pm 0.240$ \\
Reactor 2 & $\log _{10} / 24$ days & $0.73 \pm 0.150$ & $1.34 \pm 0.035$ \\
Reactor 3 & $\log _{10} / 24$ days & $0.31 \pm 0.050$ & $0.62 \pm 0.024$ \\
\hline
\end{tabular}


Figure 1
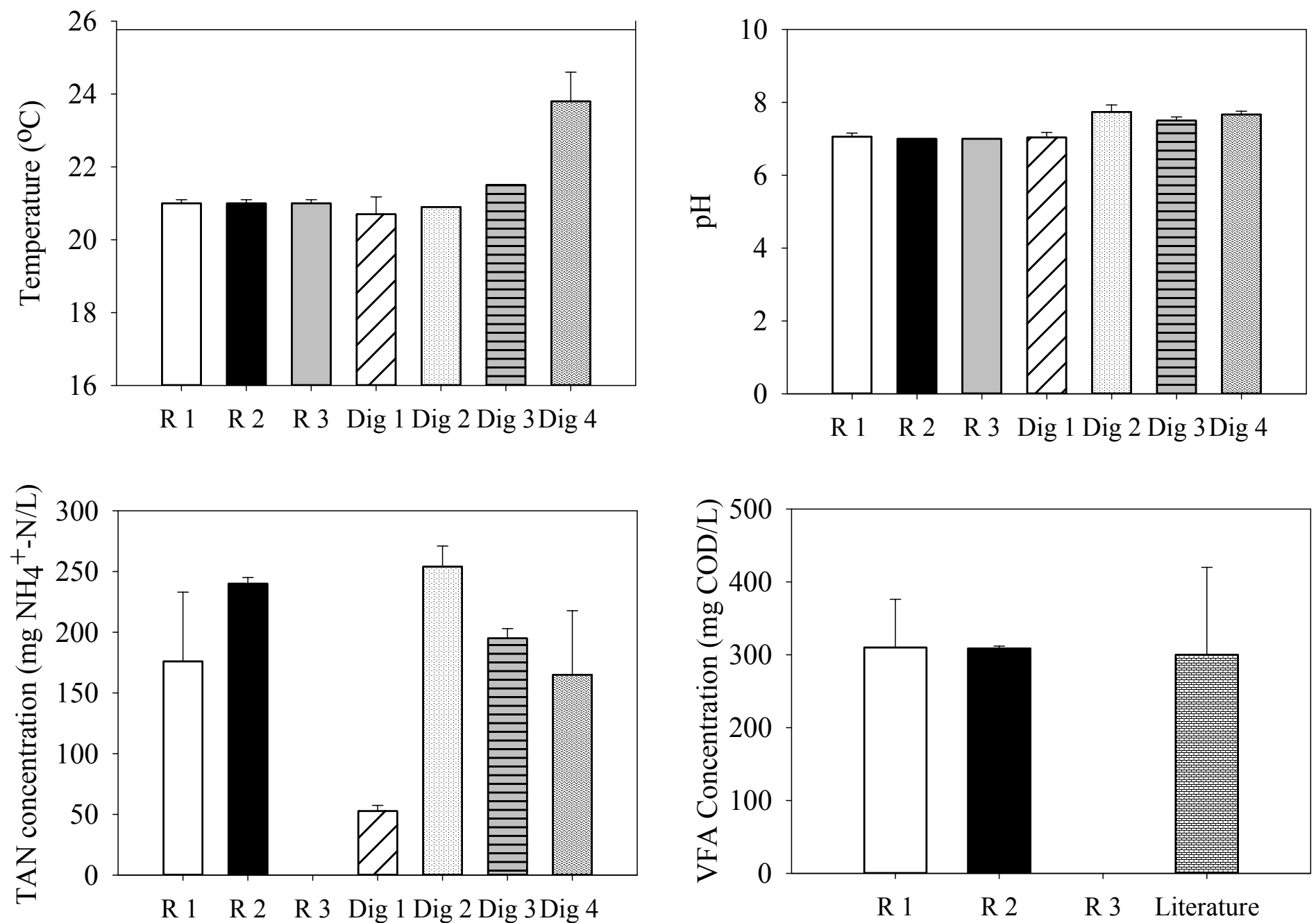

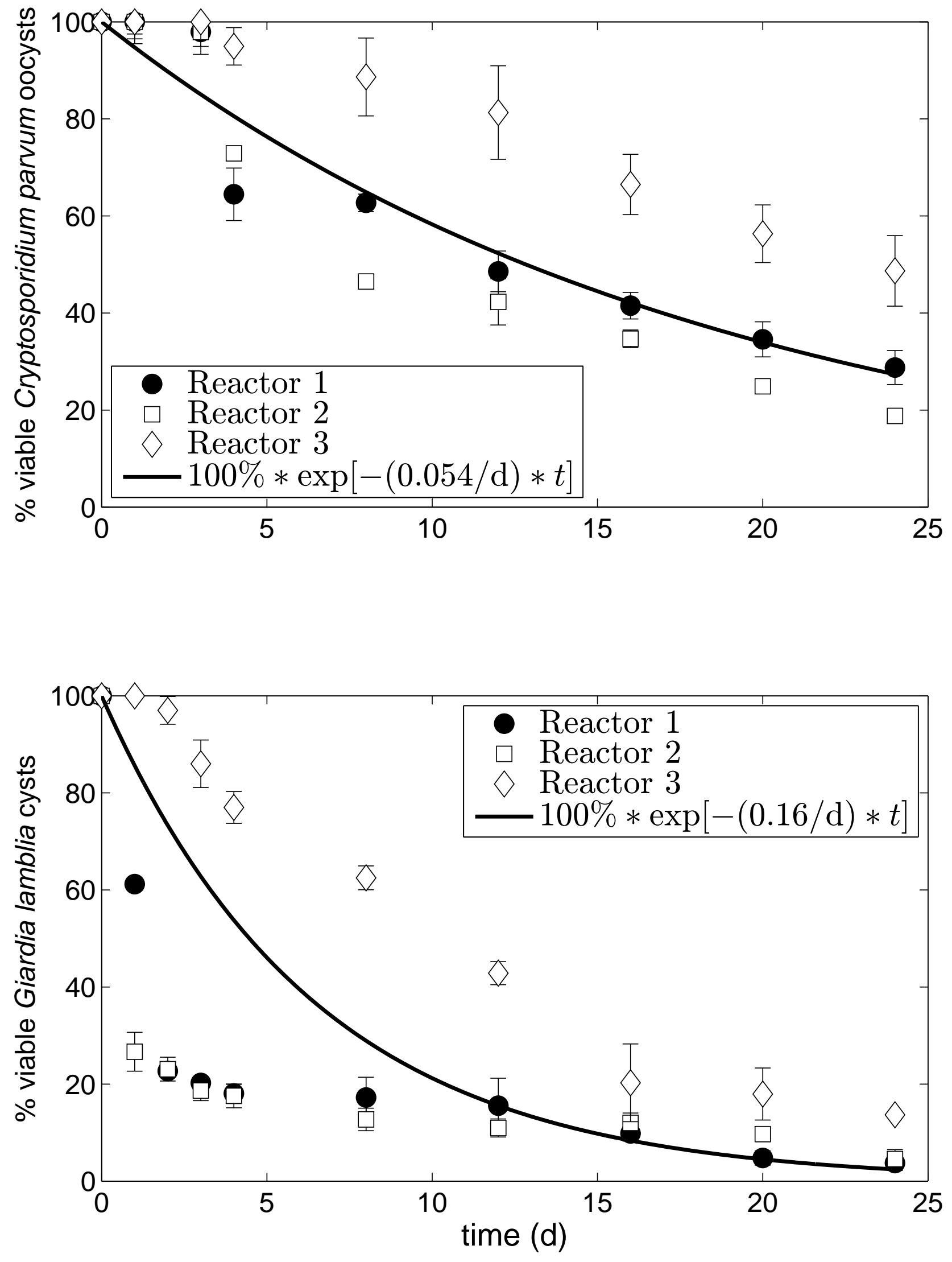

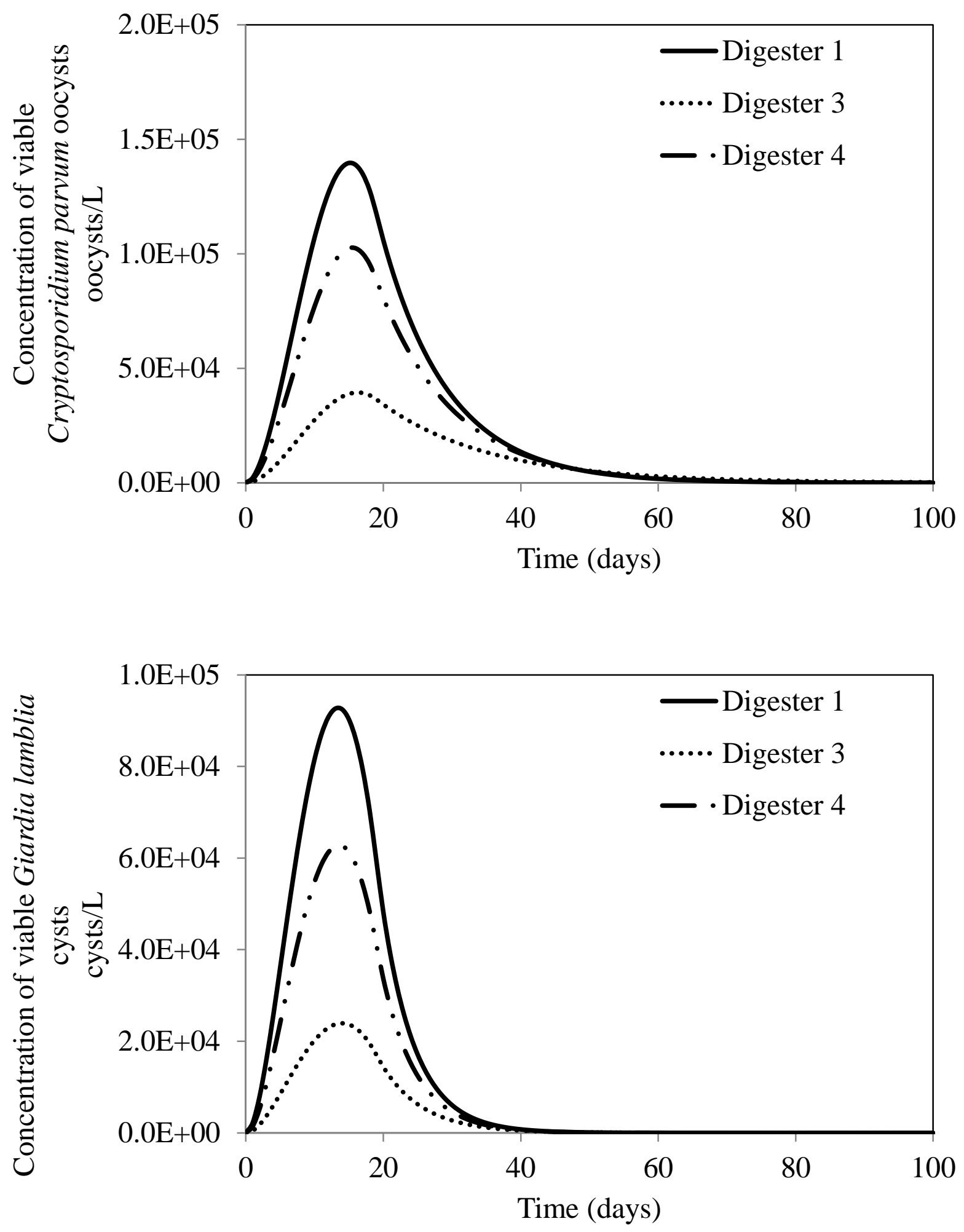
Effluent Cryptosporidium parvum oocyst concentration

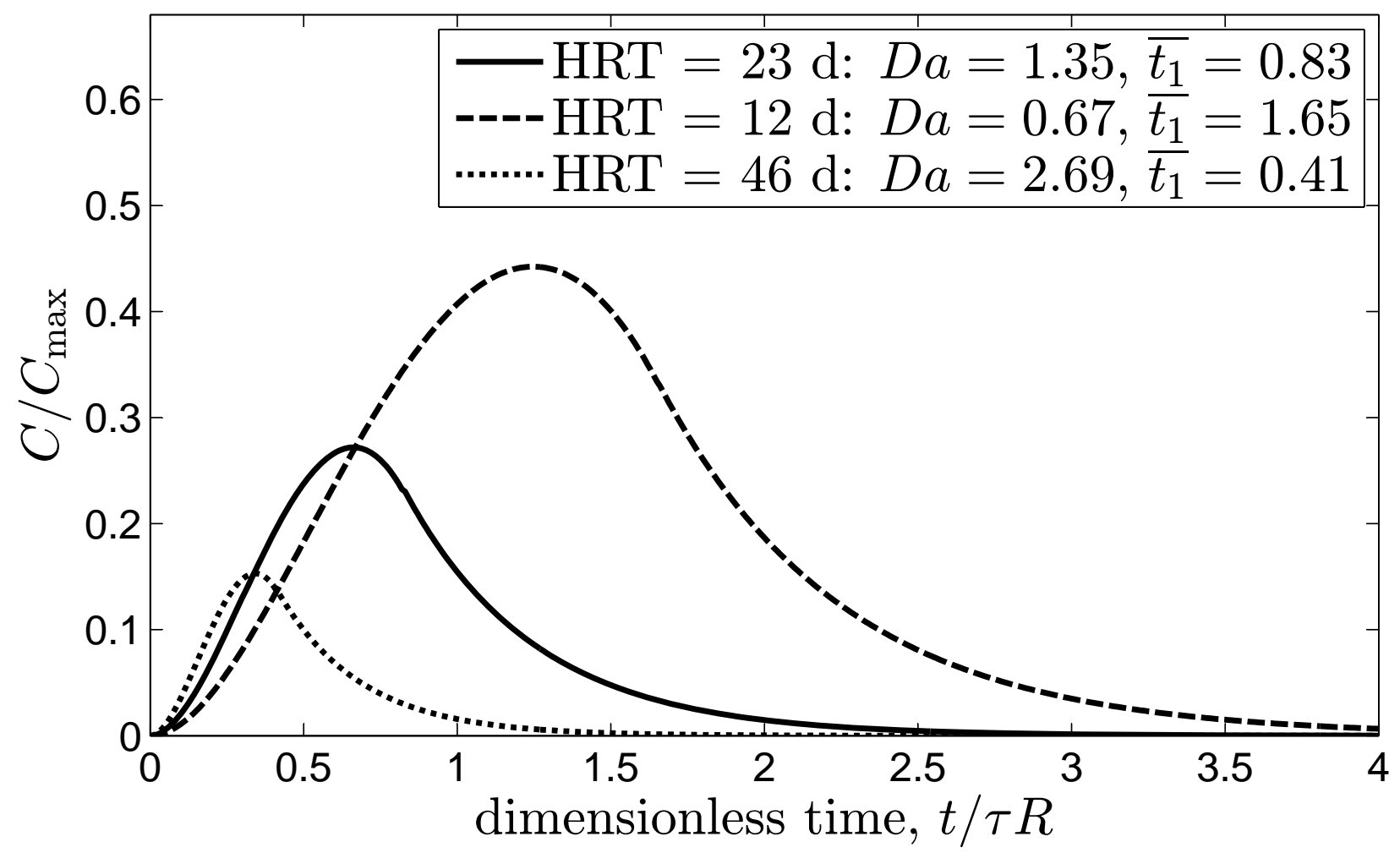

Effluent Giardia lamblia cyst concentration

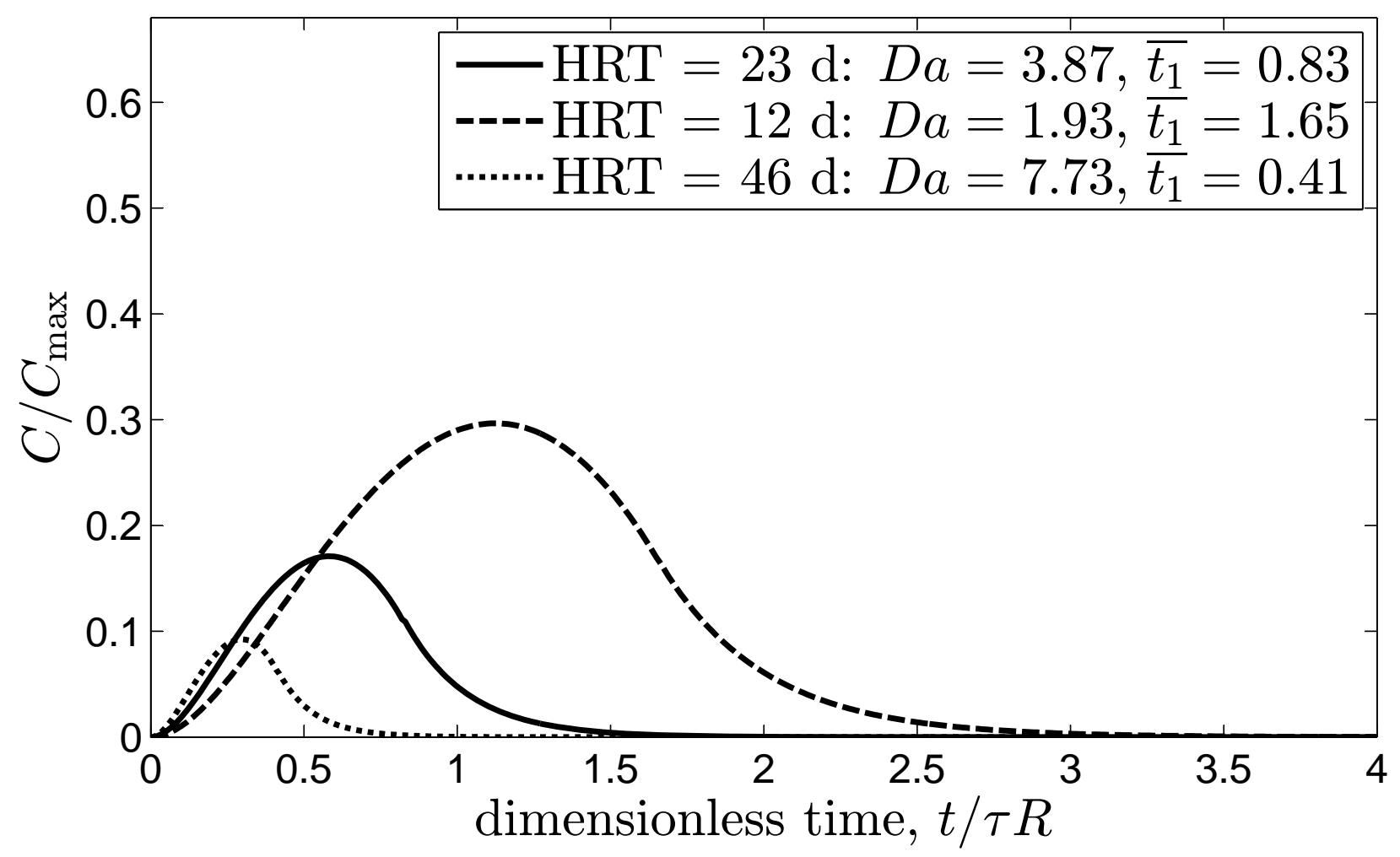




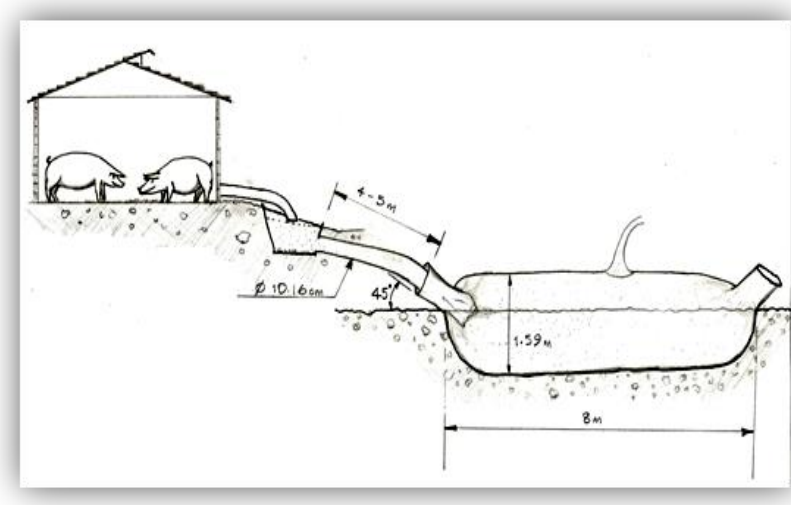

Measurements of environmental conditions, physical processes, and field interviews

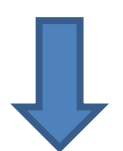

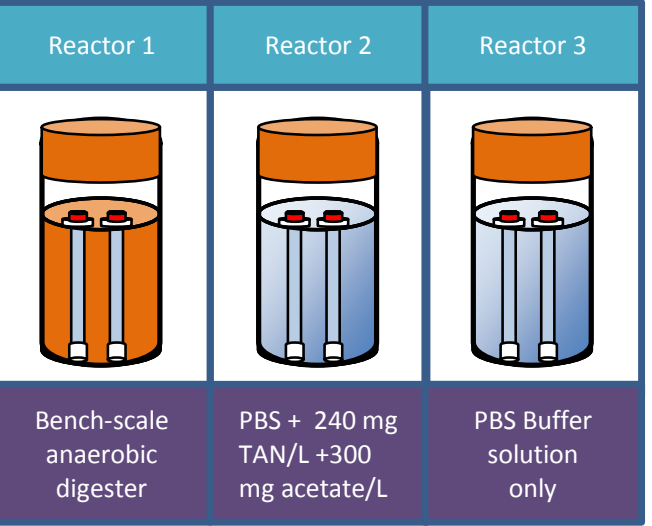

Laboratory inactivation studies under conditions similar to those in the field

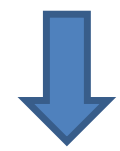

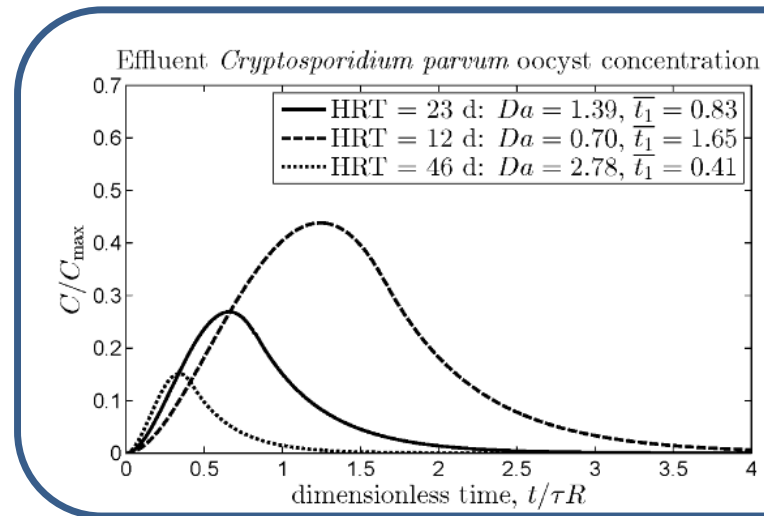

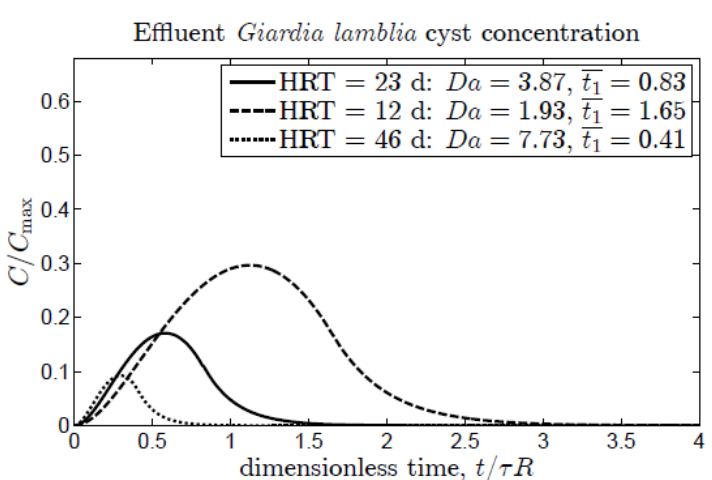

Mathematical modeling to predict effluent concentration of Cryptosporidium parvum and Giardia lamblia (oo)cysts in tubular digesters 